\title{
KNOWLEDGE AND ATTITUDES TOWARDS ORAL AND DENTAL HEALTH AMONG 7TH AND 8TH GRADE STUDENTS COMPARED WITH THEIR TEETH EXAMINATION IN MANISA, TURKEY
}

\author{
H. Dağ ${ }^{1}$, A. Kutan Fenercioğlu², H. Karınca ${ }^{3}$, E. Aygan Ozyıldız ${ }^{3}$, G. $\mathrm{Can}^{4}$, G. Karatekin ${ }^{5}$ \\ ${ }^{1}$ Paediatrics Clinic, Sarigol State Hospital, Manisa, ${ }^{2}$ Department of Family Medicine, Yeditepe University, \\ Medical Faculty, Istanbul, ${ }^{3}$ Ozylldiz Oral and Dental Health Clinic, Manisa, ${ }^{4}$ Public Health Department, \\ Cerrahpasa Medical Faculty, ${ }^{5}$ Zeynep Kamil Maternity and Children's Training and Research Hospital \\ Division of Neonatology, Istanbul, Turkey
}

\begin{abstract}
Aims: Oral and dental health are important aspects of general health and impact the quality of life and health outcomes. We aimed to assess the level of knowledge and attitudes towards oral and dental health and to examine the relative effect of social-behavioural risk factors on caries and other teeth problems among $7^{\text {th }}$ and $8^{\text {th }}$ grade students in Manisa, Turkey.
\end{abstract}

Methods: The study population consisted of all seventh and eighth graders who started the 2011 school year $(\mathrm{n}=377)$. Data were gathered by questionnaires which were carried out before tooth examination. Associations between sociodemographic characteristics, knowledge items, attitudinal factors and number of tooth caries and other tooth problems were studied. The associations were evaluated using mean values and chi square test.

Results: Oral health was worse among female gender $(\mathrm{p}=0.002)$. As the number of children under care increased in the house, number of tooth filling and tooth loss increased in the students $(p=0.001, p=0.021)$. Education of mothers of students who had worse tooth health was significantly low compared to the others $(\mathrm{p}=0.029)$. Among students who had four and more tooth caries and tooth fillings, frequency of dentist visit was lower ( $\mathrm{p}=0.034, \mathrm{p}=0.005$ ). Among students who had more tooth caries, the knowledge that consumption of acidic beverages is not good for oral health was less prevalent $(\mathrm{p}=0.011)$.

Conclusions: Health authorities in region, should strengthen the implementation of oral disease prevention and health promotion programs rather than traditional curative care. Community-oriented education programs for students and their families are crucial for this purpose. 